\title{
Identification of soil liquefaction occurrence using wavelet analysis
}

\author{
Ramin Kamran Disfani ${ }^{1} \cdot$ Amir Bazrafshan Moghaddam ${ }^{1}$ (i)
}

Received: 19 June 2020 / Accepted: 1 September 2020 / Published online: 11 September 2020

(c) Springer Nature Switzerland AG 2020

\begin{abstract}
One of the most important problems encountered during construction of structures on earthquake-suspected sites is to identify whether the site is liquefiable or not. Whenever a dynamic load such as an earthquake occurs, the strength of granular loose saturated soils decreases tremendously in a very short period of time. The shear strength of soils vanishes, and the soil changes from solid to liquid phase. This problem causes significant damage to both the structure and the foundation. Thus, it is important to determine an index which defines whether a site is liquefied. In this article, threedimensional wavelet spectra of different earthquakes are drawn, and based on changes in the frequency contents of these earthquakes, a new index is developed in order to identify liquefied and non-liquefied sites. The proposed method is simple and efficient and is able to distinguish whether soil liquefaction occurs in a site just by using recorded earthquake accelerations available at the site.
\end{abstract}

Keywords Liquefaction occurrence index · Earthquakes · Wavelet spectrum · LP wavelet · Time-frequency analysis

\section{Introduction}

Soil liquefaction is a phenomenon in which the shear strength of soil deposit vanishes in a short period of time as a result of dynamic loads such as earthquakes or explosions, changing the phase of the soil to a liquid state. Soil liquefaction reduces soil rigidity which results in phenomena such as sand boiling, slurry flows, differential settlement and landslides. Due to damage that is the consequences of soil liquefaction and their destructive effects on engineering structures, a measurement is urgently needed to determine whether a site is liquefied with the least error.

Since it is difficult and error-prone to determine dynamic properties of soil in the laboratory environment, researchers are interested in finding other methods for soil liquefaction evaluation. Therefore, different methods have been introduced in recent years to detect the occurrence of soil liquefaction.
Kostadinov and Yamazaki [1] proposed a new liquefaction detection method that simultaneously analyzes the instantaneous frequency content of horizontal and vertical ground acceleration. They considered the mean instantaneous frequency (MIF) to be defined as the ratio of the first to zero frequency moment of a time-frequency representation. Liquefaction for the desired sites is evaluated based on the values of MIF for vertical and horizontal acceleration components. Miyajima et al. [2] have proposed two indices for detection of liquefaction using amplitude and frequency characteristics of acceleration records. Hu et al. [3] defined the predominant instantaneous frequency (PIF) and introduced the PIF-related motion features to identify liquefaction conditions at a given site with the aid of the Hilbert-Huang transform. Yuan and Sun [4] proposed a new method for fast identification of liquefied-soil sites from surface acceleration records in terms of the concept of frequency decrease rate. Yuan et al. [5] presented a semi-theoretical method for straightforward identification of liquefied sites by using surface acceleration records.

Amir Bazrafshan Moghaddam, amir.bazrafshan@shahroodut.ac.ir; amir.bazrafshan@gmail.com; Ramin Kamran Disfani, r.kamrandisfani@gmail.com | 'Department of Civil Engineering, Shahrood University of Technology, Shahrood, Iran. 
They introduced the natural frequency decreasing ratio of the site as a fundamental benchmark and the time-frequency decreasing ratio of the surface acceleration as a basic index.

Some researchers have shown that the frequency features of acceleration are altered by liquefaction. These changes can be observed from ground motion accelerations. These phenomena prove that frequency content in the acceleration time histories is significantly affected by liquefaction [5-8]. Based on this fact, a new approach for detecting liquefaction occurrence is presented based on the characteristics of recorded acceleration time histories in liquefied sites, in comparison with that of non-liquefied sites.

The 3-D spectrum of different seismic records of liquefied and non-liquefied sites is obtained using wavelet analysis. Then, the volumes beneath the spectrum surface, before and after the PGA occurrence time, are calculated. The PGA occurrence time is considered as the boundary to divide the acceleration history into two parts because liquefaction usually occurs after PGA occurs. From the ratio of changes in the volume of the three-dimensional earthquake wavelet spectrum before and after the occurrence of PGA to its volume before PGA time, an index is introduced called the "liquefaction occurrence index" (LOI). This can be used to distinguish between liquefied and nonliquefied sites.

\section{Theory}

Figures 1 and 2 show acceleration time history graphs of earthquakes recorded in liquefied and non-liquefied sites, respectively. There is no obvious identification of soil liquefaction from inspecting these acceleration time history

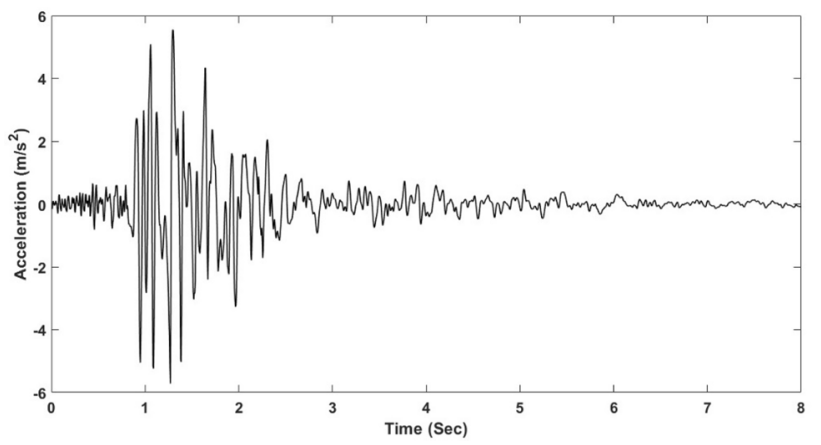

Fig. 2 Time-history acceleration of Northridge (1994) earthquake, New Hall Station (non-liquefied)

graphs. Therefore, a new method is needed to give a quantitative indication of the occurrence or non-occurrence of this phenomenon.

Since the dynamic response of structures under earthquake loads is very sensitive to their loading frequency and frequency content determines the distribution of amplitude of ground movements under different frequencies, it is hard to determine ground motion characteristics accurately without considering their frequency content.

Therefore, it is necessary to find an efficient method for analyzing in the time-frequency domain. Because we are unable to determine the exact occurrence time of a specific frequency using Fourier analysis, wavelet analysis method is used which can analyze signals in both time and frequency domains simultaneously.

Unlike Fourier-based analysis which basically uses global (non-local) sine and cosine functions, wavelet analysis uses various bases that are localized in both time and frequency to represent non-stationary signals in a more efficient process. Hence, a wavelet representation is much
Fig. 1 Time-history acceleration of Kobe (1995) earthquake, Port Island station (liquefied)

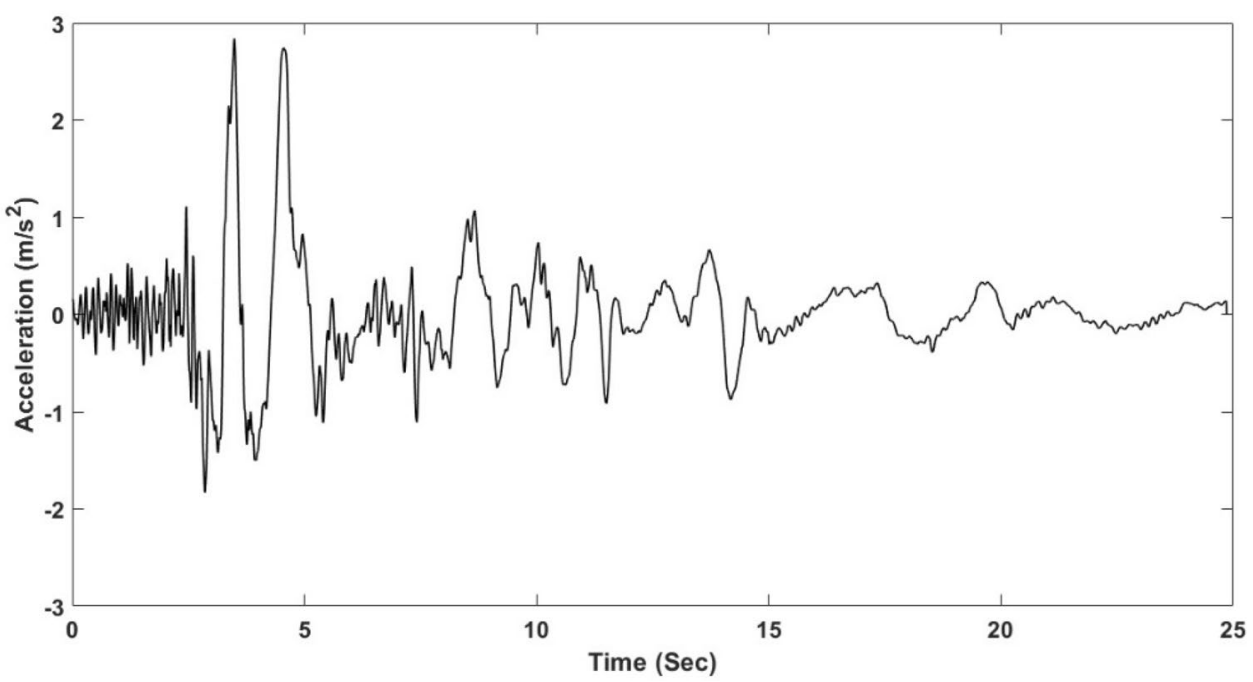


more compact and easier process to implement than the FT. This capability to represent signals compactly and at several levels of resolution is the major strength of wavelet analysis [9].

The chosen wavelet for this research is the modified Littlewood-Paley (LP) wavelet which has an excellent localization in the frequency domain [10]. This wavelet is widely used in earthquake analytical methods and it is suitable for wavelet multiresolution analysis since it has non-overlapping frequency bands [11-13]. Its mathematical expression is given as follows [10]:

$\psi(t)=\frac{1}{\pi \sqrt{\sigma-1}} \frac{\sin (\sigma \pi t)-\sin (\pi t)}{t}$

where $\sigma$ is a constant scalar which is used in discretizing the scales. Basu and Gupta [10] found that $\sigma=2^{1 / 4}$ is more suitable for earthquake motions. The integral wavelet transform of the earthquake motion is defined as [14]:

$W_{\psi} f(a, b)=\int_{0}^{T_{d}} f(t) \overline{\psi_{a, b}(t)} \mathrm{d} t$

where $\psi_{a, b}=\frac{1}{\sqrt{a}} \psi\left(\frac{t-b}{a}\right), \quad a>0$ is the translated and dilated version of mother wavelet, while $a$ and $b$ are scale and translation parameters, respectively, $f(t)$ is the recorded accelerations with total duration $T_{\mathrm{d}}$.

\section{Determination of liquefaction occurrence index}

Earthquake frequency content changes can be used to identify the resulting occurrence of soil liquefaction [5-8]. In order to determine soil liquefaction occurrence index, it should be noted that liquefaction does not necessarily occur at the exact time of PGA, but at a very short period of time before or after the PGA [4]. Figures 3 and 4 show

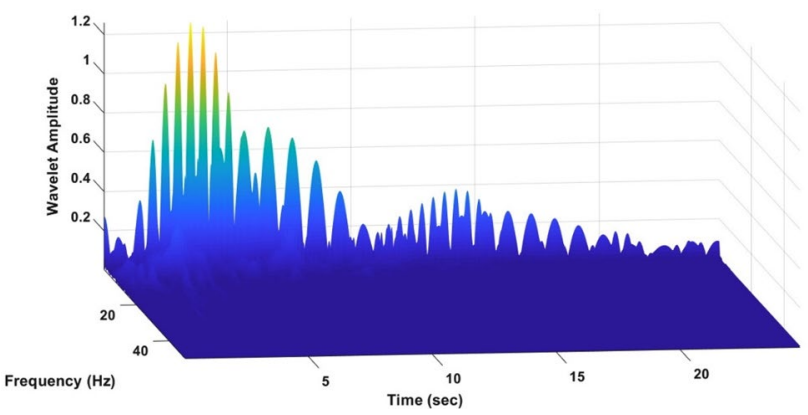

Fig. 3 Wavelet spectrum of Kobe (1995) earthquake, Port Island station (liquefied)

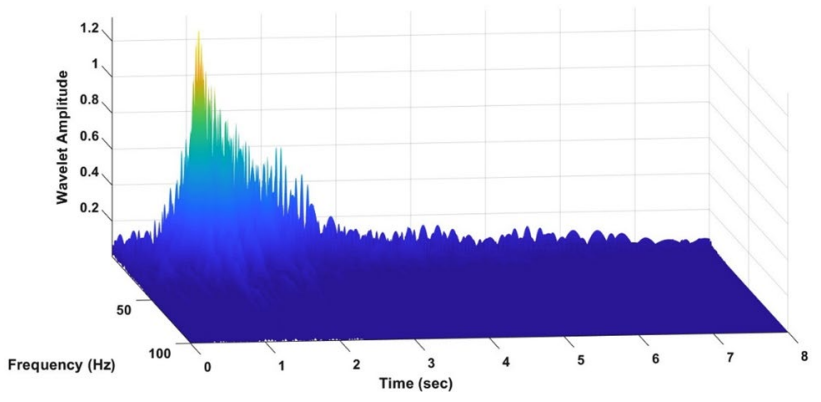

Fig. 4 Wavelet spectrum of Northridge (1994) earthquake, New Hall Station (non-liquefied)

the three-dimensional wavelet spectra of the earthquakes in Figs. 1 and 2, respectively. As shown in these figures, changes of frequency content in liquefied sites, when compared with non-liquefied sites, are seen as changes in the volume of the time-frequency 3-D wavelet spectrum curve of the earthquake. It can also be seen that the amplitudes with higher frequencies in liquefied sites have higher magnitudes than in non-liquefied sites after the time of PGA. Thus, a relation can be defined to determine whether a site is liquefied or not using the wavelet 3-D spectrum of the earthquake and studying the behavior of the earthquake site before and after the PGA time. As the frequency contents of earthquake acceleration on the soft soil layer may reduce to very low values during earthquakes (i.e., $<1 \mathrm{~Hz}$ ), soft sites and liquefied sites may be confused if the absolute variation of frequency is used as a basis. Since the initial rigidities of different soil layers before earthquakes differ, the relative variation of frequency due to liquefaction is used as the judgment index in this paper.

Therefore, in this research, a non-dimensional index called the liquefaction occurrence index (LOI) is defined as the ratio of relative changes in volume beneath the 3-D wavelet earthquake spectrum before and after the PGA time to the volume beneath the mentioned curve before PGA time. In other words,

$\mathrm{LOI}=\frac{\left|V_{b}-V_{a}\right|}{V_{b}}$

where $V_{b}$ is the volume beneath the 3-D wavelet earthquake spectrum curve before the time of PGA occurrence and $V_{a}$ is the volume beneath the 3-D wavelet earthquake spectrum curve after the time of PGA occurrence. The critical point of LOI, i.e., a value of 1.0 , is taken as a divisive point distinguishing liquefied sites from non-liquefied sites. The relations for $V_{b}$ and $V_{a}$ are expressed as: 


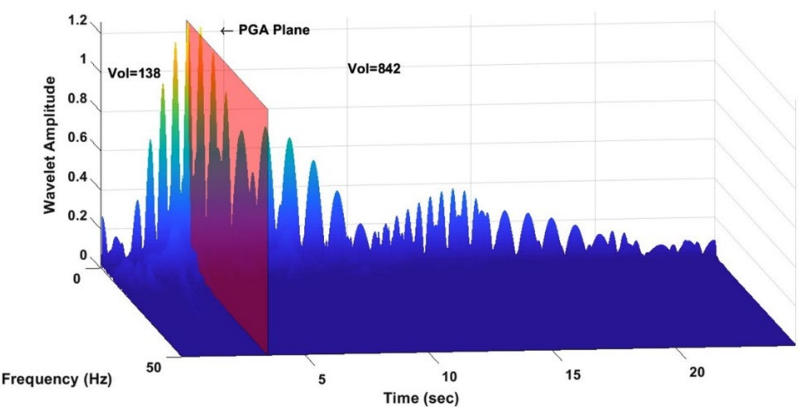

Fig. 5 LOI=5.10 for Kobe (1995) earthquake, Port Island station (liquefied)

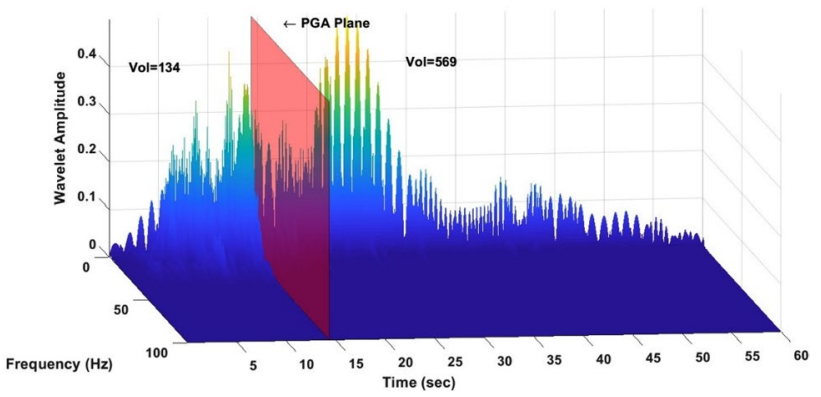

Fig. 6 LOI=3.25 for Superstition Hills (1987) earthquake, Wild Life station (liquefied)

$V_{b}=\int_{0}^{T_{\mathrm{PGA}}} \int_{a_{\mathrm{Nyq}}}^{0} \int_{0}^{T_{d}} f(t) \overline{\psi_{a, b}(t)} \mathrm{d} t \mathrm{~d} a \mathrm{~d} b$

$V_{a}=\int_{T_{\mathrm{PGA}}}^{T_{d}} \int_{a_{\mathrm{Nyq}}}^{0} \int_{0}^{T_{d}} f(t) \overline{\psi_{a, b}(t)} \mathrm{d} t \mathrm{~d} a \mathrm{~d} b$

where $a_{\text {Nyq }}=\frac{0.613}{f_{\text {Nyq }}}$ for LP wavelet [10] and $f_{\text {Nyq }}$ is Nyquist frequency.

To verify the proposed method, the behaviors of 23 earthquakes are analyzed, including 7 liquefied and 16 non-liquefied sites, which are randomly selected and LOI value is calculated separately for each site. As an example, Figs. 5, 6, 7 and 8 show the wavelet spectra of recorded earthquakes in 2 liquefied and 2 non-liquefied sites. The duration of each earthquake is determined based on the total time elapsed between the first and the last excursions of threshold acceleration of 5\% PGA [15].

The 3-D wavelet spectrum is drawn and the volume beneath each curve has been calculated before and after the time of PGA and the value of $\mathrm{LOI}$ is obtained for each

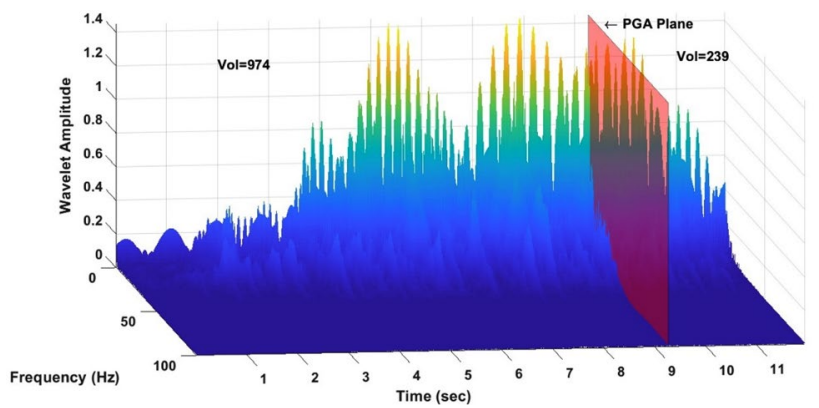

Fig. 7 LOI=0.75 for Gazli (1984) earthquake, Bukhara station (nonliquefied)

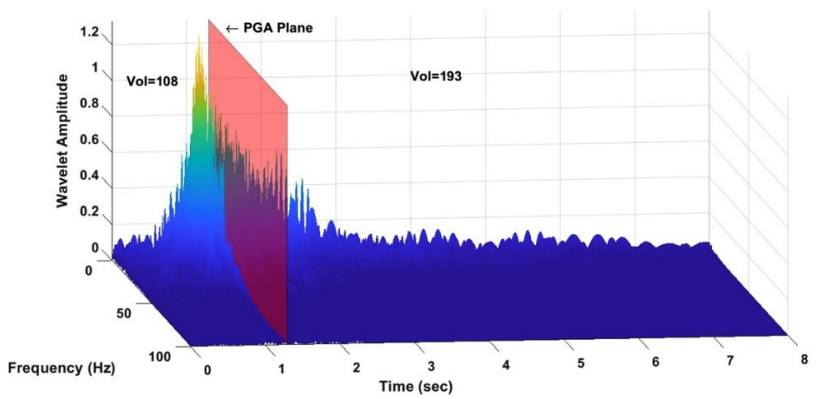

Fig. 8 LOI=0.79 for Northridge (1994) earthquake, New Hall station (non-liquefied)

site. The results of liquefaction detection are presented in Table 1, demonstrating that the proposed method can identify all of the liquefied and non-liquefied sites correctly. It can be seen from Table 1 that LOI for the non-liquefied sites is between 0.02 and 0.85 with an average value of 0.48 , while LOI for the liquefied sites is between 1.69 and 8.80 with an average value of 3.55 which verifies that there are great changes in the frequency content of liquefied sites after the time of PGA occurrence as mentioned earlier in the paper. Therefore, the threshold 1.0 presented in the paper is rational and reliable. It should be noted that for LOI values close to the threshold value (i.e., $\mathrm{LOI}=1$ ), the decision should be made with caution and further investigation is needed to determine liquefaction.

\section{Conclusion}

In this paper, a new method for fast identification of site liquefaction from surface acceleration records is presented, considering the effects of soil liquefaction on the frequency content of earthquake motion. The proposed method is capable of detecting soil liquefaction in a site just by using the earthquake accelerogram of the recorded 
Table 1 Values of LOI for liquefied and non-liquefied sites

\begin{tabular}{|c|c|c|c|c|c|}
\hline No. & Earthquake & Station & $\begin{array}{l}\text { Liquefaction } \\
\text { investigation }\end{array}$ & LOI & $\begin{array}{l}\text { Pro- } \\
\text { posed } \\
\text { method }\end{array}$ \\
\hline 1 & Cape Mendocino (1992) & Petrolia & $\mathrm{NL}$ & 0.55 & $\mathrm{NL}$ \\
\hline 2 & Northridge (1994) & Topanga & $\mathrm{NL}$ & 0.35 & $\mathrm{NL}$ \\
\hline 3 & Loma Prieta (1989) & Treasure Island & NL & 0.17 & $\mathrm{NL}$ \\
\hline 4 & Whittier Narrows (1987) & Obregon Park & $\mathrm{NL}$ & 0.77 & $\mathrm{NL}$ \\
\hline 5 & Rudbar (1990) & Manjil & $\mathrm{NL}$ & 0.04 & $\mathrm{NL}$ \\
\hline 6 & Gazli (1984) & Bukhara & $\mathrm{NL}$ & 0.75 & $\mathrm{NL}$ \\
\hline 7 & Superstition Hills (1987) & Salton Sea Wild Life Refugee & $\mathrm{NL}$ & 0.43 & $\mathrm{NL}$ \\
\hline 8 & Zarand (2005) & Zarand & $\mathrm{NL}$ & 0.55 & $\mathrm{NL}$ \\
\hline 9 & Bam (2003) & Andoohjerd & $\mathrm{NL}$ & 0.45 & $\mathrm{NL}$ \\
\hline 10 & Morgan Hills (1984) & Gilroy \#1 & $\mathrm{NL}$ & 0.16 & $\mathrm{NL}$ \\
\hline 11 & Victoria (1980) & Victoria Hospital & $\mathrm{NL}$ & 0.02 & $\mathrm{NL}$ \\
\hline 12 & Tabas (1978) & Bajestan & $\mathrm{NL}$ & 0.72 & $\mathrm{NL}$ \\
\hline 13 & Landers (1992) & Boron & $\mathrm{NL}$ & 0.58 & $\mathrm{NL}$ \\
\hline 14 & Hendek-Akyazi (2000) & Koer & $\mathrm{NL}$ & 0.51 & $\mathrm{NL}$ \\
\hline 15 & Spitak (1988) & Gukasyan & $\mathrm{NL}$ & 0.34 & $\mathrm{NL}$ \\
\hline 16 & Ghaen (1997) & Khezri & $\mathrm{NL}$ & 0.09 & $\mathrm{NL}$ \\
\hline 17 & Kobe (1995) & Port Island & $\mathrm{L}$ & 5.10 & $\mathrm{~L}$ \\
\hline 18 & Kobe (1995) & Amagasaki & $\mathrm{L}$ & 8.80 & $\mathrm{~L}$ \\
\hline 19 & Westmorland (1981) & Brawley & $\mathrm{L}$ & 6.20 & $\mathrm{~L}$ \\
\hline 20 & Superstition Hills (1987) & Wild Life & $\mathrm{L}$ & 3.25 & $\mathrm{~L}$ \\
\hline 21 & Izumi (1997) & Izumi & $\mathrm{L}$ & 2.00 & $\mathrm{~L}$ \\
\hline 22 & Nisqually (2001) & Olympia & $\mathrm{L}$ & 6.13 & $\mathrm{~L}$ \\
\hline 23 & Hokkaido (2018) & Mukawa & $\mathrm{L}$ & 8.16 & $\mathrm{~L}$ \\
\hline
\end{tabular}

$L$ liquefied, NL non-liquefied station at that site. The 3-D spectrum of different earthquake accelerations was drawn using wavelet analysis, and it was observed that higher frequencies have higher amplitudes in liquefied sites than in non-liquefied sites. In addition, the relative changes in volume beneath the 3-D wavelet spectrum before and after the time of PGA in liquefied sites are much greater than that of non-liquefied sites. Based on this fact, the liquefaction occurrence index (LOI) has been introduced and a range is obtained to distinguish between liquefied and non-liquefied sites. It is observed that if the LOI value is greater than 1 for an earthquake, soil liquefaction has certainly taken place in the recorded station; if it is less than 1, liquefaction has not occurred in the recorded site. The comparison between the predicted results by the method in the paper and the post-earthquake data indicates that the method presented here is effective to identify the site liquefaction from surface acceleration records, for both liquefied and non-liquefied sites.

Authors' contribution RKD was involved in the formal analysis, investigation and writing-original draft. $A B M$ contributed to the conceptualization, methodology, supervision, software and writing - review and editing.

Funding This research did not receive any specific grant from funding agencies in the public, commercial or not-for-profit sectors.

Availability of data and material Not applicable.

Code availability Not applicable.

\section{Compliance with ethical standards}

Conflict of interest The authors declare that they have no conflict of interest.

\section{References}

1. Kostadinov MV, Yamazaki F (2001) Detection of soil liquefaction from strong motion records. Earthq Eng Struct Dyn 30(2):173193. https://doi.org/10.1002/1096-9845(200102)30:2<173::AIDEQE3>3.0.CO;2-7

2. Miyajima M, Inagaki S, Nishikawa H, Kitaura M (2004) Detection of ground failure by using strong ground motion records. In: 13th World conference on earthquake engineering: conference proceedings, Vancouver, Canada. CD-ROM 
3. Hu Y, Zhang Y, Liang J, Zhang RR (2005) Recording-based identification of site liquefaction. Earthq Eng Eng Vib 4(2):181-189. https://doi.org/10.1007/s11803-005-0001-3

4. Yuan X, Sun R (2008) A new method for fast identification of liquefied-soil site from surface acceleration records. Paper presented at the The 14th world conference on earthquake engineering, Beijing, China,

5. Yuan X, Sun R, Chen L, Tang F (2010) A method for detecting site liquefaction by seismic records. Soil Dyn Earthq Eng 30(4):270279. https://doi.org/10.1016/j.soildyn.2009.12.003

6. Kostadinov M, Towhata I (2002) Assessment of liquefactioninducing peak ground velocity and frequency of horizontal ground shaking at onset of phenomenon. Soil Dyn Earthq Eng 22(4):309-322. https://doi.org/10.1016/S0267-7261(02)00018-0

7. Kamagata S, Takewaki I (2015) Non-linear transient behavior during soil liquefaction based on re-evaluation of seismic records. Soil Dyn Earthq Eng 71:163-184. https://doi.org/10.1016/j.soild yn.2015.01.017

8. Kramer SL (2018) Past, present, and future developments in liquefaction hazard analysis. In: lai S (ed) Developments in earthquake geotechnics. Springer, Berlin, pp 51-60. https:// doi.org/10.1007/978-3-319-62069-5_3

9. Bazrafshan MA, Bagheripour MH (2012) Earthquake timefrequency analysis using a new compatible wavelet function family. Earthq Struct 3(6):839-852. https://doi.org/10.12989/ eas.2012.3.6.839
10. Basu B, Gupta VK (1998) Seismic response of SDOF systems by wavelet modeling of nonstationary processes. J Eng Mech 124(10):1142-1150. https://doi.org/10.1061/ (ASCE)0733-9399(1998)124:10(1142)

11. Chang C-C, Shi Y (2010) Identification of time-varying hysteretic structures using wavelet multiresolution analysis. Int J NonLinear Mech 45(1):21-34. https://doi.org/10.1016/j.ijnonlinme c.2009.08.009

12. Das S, Gupta VK (2010) Scaling of response spectrum and duration for aftershocks. Soil Dyn Earthq Eng 30(8):724-735. https ://doi.org/10.1016/j.soildyn.2010.03.003

13. Das S, Gupta VK (2011) A wavelet-based parametric characterization of temporal features of earthquake accelerograms. Eng Struct 33(7):2173-2185. https://doi.org/10.1016/j.engst ruct. 2011.03 .008

14. Radunovic DP (2009) Wavelets from math to practice. Springer, Berlin

15. Bommer JJ, Martinez-Pereira A (1999) The effective duration of earthquake strong motion. J Earthq Eng 3(02):127-172. https:// doi.org/10.1142/S1363246999000077

Publisher's Note Springer Nature remains neutral with regard to jurisdictional claims in published maps and institutional affiliations. 